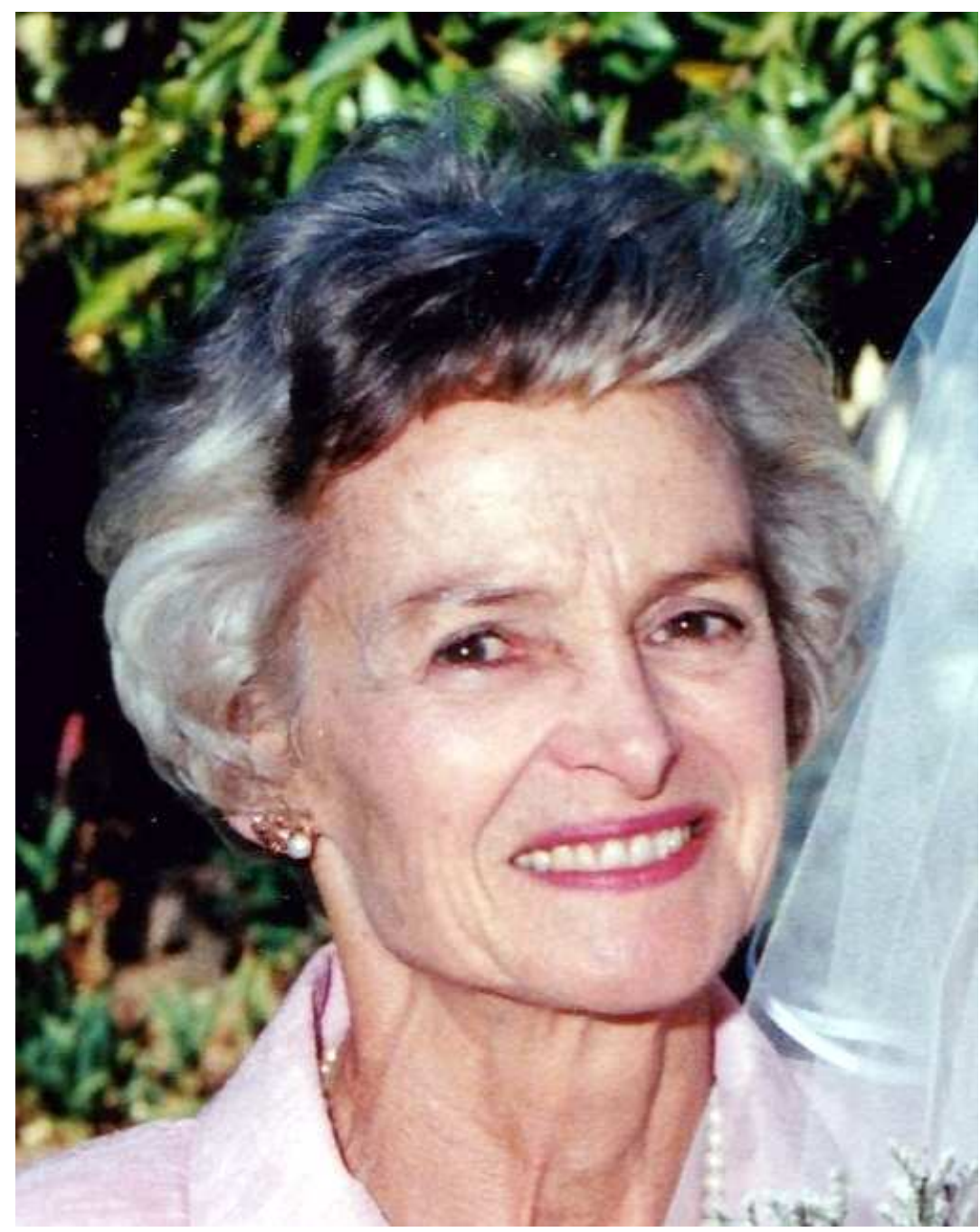

Sheelagh de Vries 


\section{IN MEMORIAM: SHEELAGH FITZPATRICK DE VRIES (03.02.1922-26.10.2014)}

All those privileged to have had Sheelagh as Latin or Classical Culture lecturer can confirm that she was the best teacher and the kindest person they had ever met. After a lifetime of service to others, Sheelagh passed away on 26 October 2014, aged 94.

Sheelagh Fitzpatrick was born on 3 February 1922 and grew up in Cradock, Eastern Cape, where she attended a convent school. She was only 16 when she passed her matriculation examination, taking first place in the then Cape Province. For the following twelve years, she worked in various positions, from executive assistant to graphic artist and assistant teacher, even serving a year in post-war Holland and England as volunteer for a Catholic charity.

By 1950, aged 28, Sheelagh undertook a new challenge, registering at Stellenbosch for a BA in English and Latin, and then achieving a Higher Education Diploma. She wanted to know more about Afrikaner culture, which was often disparaged in her English-speaking milieu. Needless to say, all her aims were successfully achieved, culminating in marriage to an Afrikaans speaker, Jan de Vries, in 1957. Thereafter she devoted herself to raising their three children, returning to the University only intermittently.

In every position she filled, Sheelagh earned the respect of all colleagues with her meticulous attention to detail. While working as Latin's Departmental Assistant, she contributed hugely to the early successes of this journal. Later she taught Latin at Paul Roos Gymnasium.

During 1979 to 1980 it was my privilege to get to know Sheelagh in a new capacity, as keen, brilliant student, at last coming back to the Honours studies in Latin that she had laid aside for family reasons. Her sharp intellect and selfdeprecating sense of humour made every session with her a rare treat for both her lecturers and her classmates.

At an age when many start enjoying the fruits of retirement, Sheelagh in 1983 took a four-year contract position as lecturer, inspiring further cohorts of Latin Beginners and first year students. The various senior courses she taught were characterized by her thorough preparation and soft-spoken wit.

Sheelagh's was truly a life well lived. In the words of her son Pierre: 'She is an inspiration for all those who dare to reach across the lines of religion, gender and language group, who persistently seek knowledge in spite of daily obstacles, and who see the Classics as a vital and important part of our culture'.

Jo-Marie Claassen 